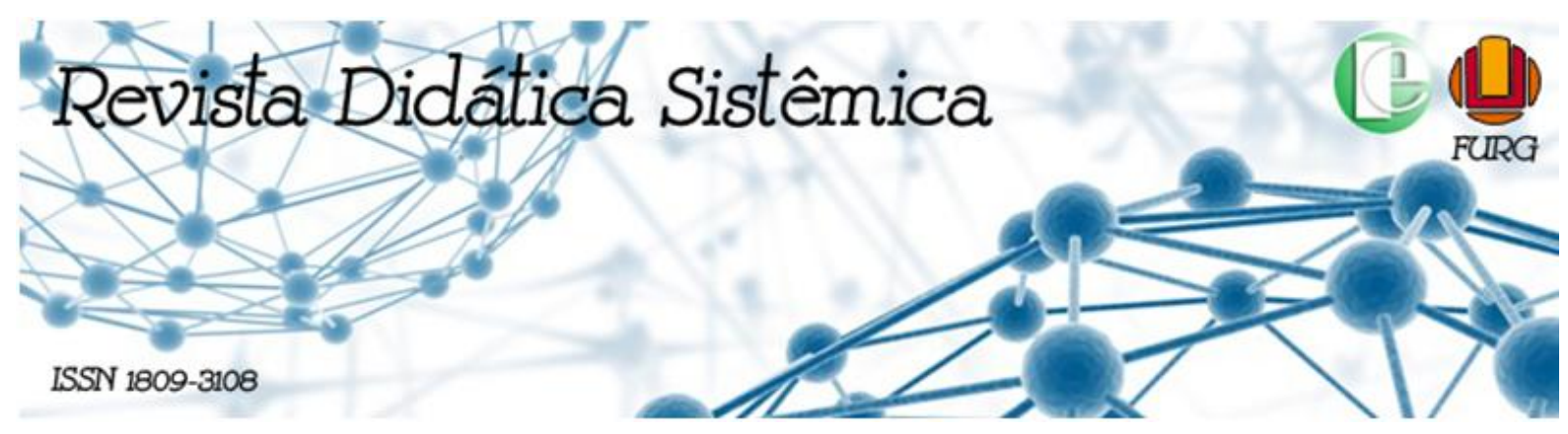

\title{
AS POLÍTICAS DE AÇÕES AFIRMATIVAS NA FURG: PRINCÍPIOS E CONCEITOS QUE POSSIBILITAM UMA REFLEXÃO ACERCA DOS DIFERENTES ASPECTOS DA DIVERSIDADE PRESENTES NA UNIVERSIDADE
}

\author{
Daniele Barros Jardim* \\ Humberto Calloni**
}

\section{RESUMO}

Este trabalho objetiva apresentar e compreender as políticas de Ações Afirmativas, principalmente, na Universidade Federal do Rio Grande - FURG, a partir de um apanhado de princípios e conceitos internacionais, nacionais e locais, que possibilitam a reflexão acerca dos diferentes aspectos da diversidade presentes na Universidade. Para tanto, foi realizado um levantamento bibliográfico histórico e conceitual da relação destas políticas com a reparação histórica dos indivíduos, que, no decorrer dos tempos, foram, e ainda são, discriminados, seja racialmente, historicamente, seja socialmente. Dessa forma, as Ações Afirmativas descontroem discursos e acarretam a reinvenção de novas práticas educativas e relações interpessoais na Universidade, mas, por vezes, se torna uma política discriminada por não oportunizarem a reflexão sobre o assunto.

Palavras-chave: Ações Afirmativas. Políticas públicas. Diversidade. Universidade.

\section{THE AFFIRMATIVE ACTION POLICIES IN FURG: PRINCIPLES AND CONCEPTS THAT ALLOW A REFLECTION ON THE DIFFERENT ASPECTS OF DIVERSITY PRESENT IN THE UNIVERSITY}

\section{ABSTRACT}

This paper aims to present and understand the policies of Affirmative Actions mainly at the Federal University of Rio Grande - FURG, based on a collection of international, national and local

\footnotetext{
* Pedagoga na Pró-Reitoria de Assuntos Estudantis - PRAE, da Universidade Federal do Rio Grande FURG. Doutoranda em Educação Ambiental (PPGEA/FURG). Desenvolve suas atividades nos seguintes temas: Assistência Estudantil; Ações Afirmativas; Educação Ambiental; Educação Infantil e Educação a Distância. Licenciada em Pedagogia - Hab. Educação Infantil e Didática (FURG, 2006); Especialização em Psicopedagogia Institucional (Portal Faculdades, 2008) e Mestre em Educação Ambiental (FURG, 2010).

** Graduado em Filosofia pela Universidade Federal do Rio Grande do Sul (1985). Graduado em Pedagogia pela Universidade Federal do Rio Grande do Sul(1987). Mestre em Educação pela Universidade Federal do Rio Grande do Sul (1990). Doutor em Educação pela Universidade Federal do RS (2002). Professor da Universidade Federal do Rio Grande. Revisor de periódico da Ambiente \& Educação. Revisor de periódico da Cadernos de Educação (UFPel). Revisor de periódico da Momento (Rio Grande). Revisor de periódico da Revista Espaço Acadêmico (UEM). Revisor de periódico da Revista Eletrônica do Mestrado em Educação Ambiental. Revisor de projeto de fomento do Coordenação de Aperfeiçoamento de Pessoal de Nível Superior. Revisor de periódico da KÍNESIS (MARÍLIA). Tem experiência na área de Educação, com ênfase em Fundamentos da Educação, atuando, principalmente, nos seguintes temas: interdisciplinaridade, diálogo, formação e humanismo.
} 
principles and concepts that allow reflection on the different aspects of diversity present in the University. For that, a historical and conceptual survey of the relationship between these policies and the historical reparation of individuals, which in the course of time were and are still discriminated, racially, historically or socially. Thus Affirmative Actions disrupt speeches and entail the reinvention of new educational practices and interpersonal relations in the University, but sometimes it becomes a discriminated policy for not opportunizing the reflection on the subject.

Keywords: Affirmative Actions. Public policy. Diversity. University.

\section{LAS POLÍTICAS DE ACCIÓN AFIRMATIVA EN FURG: PRINCIPIOS Y CONCEPTOS QUE PERMITEN UNA REFLEXIÓN SOBRE LOS DIFERENTES ASPECTOS DE LA DIVERSIDAD PRESENTES EN LA UNIVERSIDAD}

\section{RESUMEN}

El objetivo de este trabajo es presentar y comprender las políticas de Acción Afirmativa principalmente en la Universidad Federal de Río Grande - FURG, basadas en una colección de principios y conceptos internacionales, nacionales y locales que hacen posible reflexionar sobre los diferentes aspectos de la diversidad presentes en la Universidad. Con este fin, se llevó a cabo una encuesta histórica y conceptual de la relación de estas políticas con la reparación histórica de los individuos, que con el tiempo han sido y siguen siendo discriminados, ya sea racial, histórica o socialmente. De esta manera, las Acciones Afirmativas relajan los discursos y conducen a la reinvención de nuevas prácticas educativas y relaciones interpersonales en la Universidad, pero, a veces, se convierte en una política discriminada por no permitir la reflexión sobre el tema.

Palabras clave: Acciones Afirmativas. Políticas públicas. Diversidad. Universidad.

\section{INTRODUÇÃO}

Embora, no contexto nacional, esteja latente a temática das Ações Afirmativas, principalmente a partir da Lei 12.711 (LEI FEDERAL de 29/08/2012) - que trata sobre modalidades de ingresso nas universidades e institutos federais e de outros projetos e ações que estão sendo desenvolvidas - muitas pessoas ainda não entendem ou não compreendem o que são Ações Afirmativas, o que leva, por vezes, ao preconceito por estas políticas. No cenário brasileiro atual, quando mencionamos a questão das Ações Afirmativas, automaticamente, nos remete ao sistema de cotas, contudo não é a única medida. Em geral, as Ações Afirmativas devem estar relacionadas à reparação de indivíduos que, ao longo do tempo, foram discriminados, seja na forma racial, social, seja histórica.

As Ações Afirmativas são políticas praticadas com o objetivo de minimizar as desigualdades, em sua maioria, históricas, oportunizando equidade de oportunidades às pessoas e/ou grupos, reparando privações provocadas pela discriminação e marginalização, decorrentes de motivos sociais, raciais, étnicos, religiosos, de gênero, entre outros (FONSECA, 2009). 
De acordo com Zoninsein e Feres Júnior (2006), Ação Afirmativa é um tema interessante e desafiador para o pensamento acadêmico, pois desconstrói discursos e práticas e constitui-se num novo processo de pensar nos indivíduos em geral e na coletividade em especial. As Ações Afirmativas emergem de uma condição que precede e vai além das políticas atuais que se dizem transitórias e estão intrinsecamente relacionadas à proposta da Política Nacional de Educação Ambiental (1999). Por exemplo, uma vez que suas ações destinam-se a assegurar, mediante a educação, a integração das múltiplas dimensões da sustentabilidade, tais como: ambiental, social, ética, cultural, econômica, espacial e política.

Mediante as Ações Afirmativas, é possível a reinvenção de sentidos das práticas educativas e das relações interpessoais, pois estimulam o desenvolvimento de ações transformadoras, contribuindo, assim, como alternativa na superação da crise socioambiental que vivenciamos. Para Freire (1987), a educação deve permitir que os oprimidos possam recuperar o seu senso de humanidade e, por sua vez, superar a sua condição, para tanto, o indivíduo oprimido deve desempenhar um papel na sua libertação. Dessa forma, compreender como estas ações se constituíram ao longo do tempo, no contexto internacional e local, é de extrema relevância para que se fortaleçam estas medidas, até que se avalie a desnecessidade das mesmas.

\section{CAMINHOS METODOLÓGICOS}

Com o intuito e interpretar o fenômeno que observamos e vivenciamos sobre as Ações Afirmativas na FURG, foi realizado um levantamento bibliográfico histórico e conceitual da relação destas políticas com a reparação histórica dos indivíduos, que, no decorrer dos tempos, foram, e ainda são, discriminados, seja racialmente, historicamente, seja socialmente, permitindo-nos conhecer mais sobre o assunto (MINAYO, 2010). Estabelecemos estratégias de pesquisa tanto nos textos acadêmicos utilizados como em base de dados de produções científicas publicadas.

Dessa banda, foi realizada a investigação no banco de dados da Biblioteca Brasileira Digital de Teses e Dissertações - BDTD em outubro de 2018, com o objetivo de angariar os trabalhos concluídos e publicados até a referida data. A BDTD disponibiliza, em seu portal de busca, teses e dissertações defendidas nas instituições brasileiras de ensino e pesquisa, sem quaisquer custos. 
Inicialmente, procedeu-se à busca filtrando as publicações que continham os termos "Ações Afirmativas" nos títulos e "educação" como assuntos, o que gerou o resultado de 55 trabalhos entre teses e dissertações. Desses, 15 teses e 40 dissertações registradas entre 2000 e 2018, com os seguintes temas abordados, relacionados com as Ações Afirmativas: Ensino Superior, Ensino Superior EaD, População Negra, Movimentos Negros, Perfil étnico-racial, Desigualdades raciais, Políticas de saúde, Sistema de cotas, Institutos Tecnológicos, Inclusão Social, Estudantes com deficiência, Vestibular, América Latina, Direito, Resiliência, Ações Ambientais Afirmativas, Indígenas, Permanência, Docentes e Processos Seletivos Específicos Indígena e Quilombola.

Notou-se que, no ano de 2000, foi concluída a primeira dissertação registrada sobre Ações Afirmativas no Ensino Superior na plataforma pesquisada e, somente em 2007, a primeira tese, relacionando as Ações Afirmativas com o movimento negro e a educação. O ano com mais publicações de produções científicas com este tema foi 2015 , totalizando nove trabalhos - cinco dissertações e quatro teses, todas abordando diretamente o tema mencionado com o Ensino Superior no Brasil. Sendo que, entre 2001 e 2005, não obtivemos registros de publicações de dissertações e teses.

Em seu conjunto, estes trabalhos demonstram que o sistema de Educação Superior no Brasil sofreu e sofre influências a cada projeto político e econômico nacional que se estabelece. Então, mais do que nunca, é preciso entender o papel da Educação Superior nesse cenário, uma vez que estamos caminhando em passos largos na produção de mais-valia ${ }^{1}$, tanto na formação de profissionais quanto na geração de tecnologias e inovações a serviço da reestruturação capitalista, com capital produtivo.

Portanto, é imprescindível compreender os caminhos das políticas nesse nível de ensino e das políticas educacionais no Brasil, de forma geral, bem como conhecer como procede esse tema no contexto internacional, uma vez que consideramos a educação fundamento social, econômico e ambiental. Tais produções acadêmicas destacam as Ações Afirmativas na Educação Superior e vinculam a educação como um processo de aprendizagem, que propicia ao sujeito criar uma visão crítica de sua realidade social, econômica, política e cultural.

\footnotetext{
${ }^{1}$ Nesse sentido, a noção de "mais valia" refere-se à expressão criada por Karl Marx (1818-1883), que significa o valor da força de trabalho despendida pelo trabalhador na produção e que não é remunerada. Isto é, o processo de exploração da mão de obra assalariada utilizada na produção, neste caso, na educação.
} 


\section{AS AÇÕES AFIRMATIVAS NO CONTEXTO INTERNACIONAL}

As demandas sobre Ações Afirmativas no contexto internacional surgiram, primeiramente, nos Estados Unidos, durante a luta dos negros contra o racismo em 1941, com a assinatura de um decreto pelo presidente Franklin Roosevelt, proibindo a discriminação racial contra os negros. Em 1964, com a promulgação da Lei dos Direitos Civis, pelo presidente Lyndon Johnson, este defendia que não poderíamos acreditar que duas pessoas teriam as mesmas chances para atingir um objetivo, uma vez que as condições iniciais de algumas eram desfavoráveis às outras (BRANDÃO, 2005).

Contudo, o termo "Ação Afirmativa" foi criado por outro presidente americano em 1961, John Kennedy, ao instalar uma Comissão por Oportunidades Iguais de Emprego, utilizando a expressão “affirmative action”, mas só foram ser inseridas enquanto políticas concebidas entre as décadas de 60 e 70, quando ocorreu a primeira iniciativa governamental dessa política, na forma da Lei da Oportunidade Igual no Emprego.

Tal medida ocorreu, principalmente, pela pressão da sociedade civil, especialmente do movimento negro, tanto os do tipo pacíficos, liderado por Martin Luther King e Malcon $\mathrm{X}$, e os do tipo radicais, como as "Panteras Negras", que pregavam a reação armada ante a discriminação da população negra.

No entanto, nessa época, os sistemas adotados beneficiavam, evidentemente, a classe média negra ao invés das demais classes baixas. Sendo que a pretensão inicial destas políticas nos Estados Unidos era de diminuir a discriminação social e ser um importante fator de busca pela igualdade.

Depois disso, muitas discussões foram acentuadas em torno das Ações Afirmativas americanas, principalmente, porque a maioria estava a favor do fim dessa política, justificando que as medidas eram inconstitucionais. Por volta dos anos 2000, mediante alguns julgamentos contraditórios com relação à reserva de vagas em algumas universidades, a Suprema Corte americana decidiu se manifestar e constatou que essa política é constitucional, mas não a forma como é adotada, principalmente utilizando as cotas raciais.

Antes, uma forma de justificar a Ação Afirmativa nos Estados Unidos era que a mesma trazia igualdade, imparcialidade e justiça restaurativa, mas essa política só conseguiu se consolidar quando passou a promover essa ação como contribuição para a diversidade educacional. Dessa forma, entendia-se que as políticas afirmativas trariam 
benefícios educacionais, principalmente, nas relações interpessoais, evidenciando que estas ações contribuem, de forma significativa, para a construção de uma sociedade racialmente mais igualitária.

Assim, tais políticas, nos Estados Unidos, continuam até os dias de hoje, principalmente, como movimento de inclusão. Tais políticas já foram implantadas, também, na Inglaterra, Canadá, Índia, Alemanha, Austrália, Nova Zelândia e Malásia, por exemplo. Apesar das críticas contra essas políticas de Ação Afirmativa, a experiência, nesses países, apresentam significativas mudanças alcançadas, como o crescimento da classe média da população negra, representações em cargos no governo federal e mais estudantes oriundos de escolas públicas nas universidades e, consequentemente, mais profissionais negros no mercado de trabalho.

\section{AS AÇÕES AFIRMATIVAS NO CONTEXTO BRASILEIRO}

No cenário brasileiro, uma das primeiras propostas no viés afirmativo iniciou timidamente entre os anos 1960 e 1970, a partir da aprovação de uma Lei que obrigava as empresas privadas a manterem percentagem mínima de empregados negros em seus quadros de funcionários, buscando, com esse advento, a discriminação racial no mercado de trabalho. Em nossa Constituição de 1988, em seu artigo 37, inciso VIII, traz outra medida importante dirigida às pessoas com deficiência. Depois, com a Lei 8.112, de 1990, estabelece $20 \%$ de cota para as pessoas com deficiência no serviço público brasileiro.

Em 1996, o governo do Distrito Federal tornou obrigatória a representação das etnias em propagandas institucionais do governo, nas seguintes proporções: $54 \%$ brancos, 40\% pardos, 5\% negros e 0,11 índios. Ainda em 1996, o governo federal organizou um seminário denominado "Multiculturalismo e racismo: o papel da Ação Afirmativa nos Estados democráticos contemporâneos", o qual obteve a participação de importantes figuras nacionais e internacionais, principalmente norte-americanos, a fim de discutir a implementação dessas políticas no Brasil.

Entretanto, somente a partir de 2001 que o governo federal adotou, por meio de portaria, que a cota de $20 \%$ dos cargos da estrutura institucional de seus ministérios fossem preenchidos por negros, mas não estabeleceu critérios objetivos para as escolhas das pessoas aptas ao preenchimento desses cargos (BRANDÃO, 2005). Em 2003, foi a vez da portaria sobre a cota de $20 \%$ para mulheres e de $5 \%$ para pessoas com deficiência em cargos sem vínculo empregatício, como cargos de confiança e funções terceirizadas 
nos ministérios. Contudo, é importante ressaltar que as políticas de Ações Afirmativas não se limitam apenas ao combate contra a discriminação racial, mas também a todas as formas de discriminação existentes.

Em maio de 2002, o governo federal não só instituiu o Programa Nacional de Ações Afirmativas, que institucionaliza o estabelecimento de metas percentuais de participação de afrodescendentes, mulheres e pessoas com deficiência no preenchimento de cargos em comissão; bem como adotou critérios de pontuação e inclusão de metas percentuais destes mesmos nas contratações de empresas prestadoras de serviço, entre outros (BRANDÃO, 2005).

No final de 2002, foi criado pelo governo federal o Programa Diversidade na Universidade, visando ampliar a inclusão social e combater a discriminação racial por meio de apoios e financiamentos a instituições públicas, privadas e à sociedade civil, dispostas a promoverem cursos a negros e indígenas. Ao realizar esse tipo de política afirmativa, tanto na esfera pública quanto na privada, busca-se concretizar um princípio constitucional de igualdade material, bem como amenizar as mais diversas discriminações que possam existir, tais como: racial, de gênero, de idade, de origem, física entre outras.

Segundo alguns autores, as políticas de Ações Afirmativas simbolizam medidas compensatórias de resgate histórico de discriminação, uma ação alternativa para enfrentar a desigualdade social e a concretização da justiça social e de reconhecimentos dos grupos historicamente excluídos.

Porém, é notório o fato de que só foi possível o advento das Ações Afirmativas, no Brasil, após a "Conferência Mundial contra o Racismo, Discriminação Racial, Xenofobia e Intolerância Correlata", realizada em setembro de 2001, em Durban. Foi mediante o documento final produzido naquele evento que se teve um saldo no debate e na adoção de programas de Ação Afirmativa no Brasil, pois, anteriormente, pode-se dizer que existiam somente iniciativas pontuais.

As ações, no Brasil, antes de 2001, já indicavam uma série de iniciativas em curso, mas ainda não se utilizava o termo "Ação Afirmativa" para denominá-las, principalmente as que buscavam atingir a igualdade racial no País. Segundo Zoninsein (2006), numa pesquisa realizada para analisar as Ações Afirmativas no Brasil no período de setembro de 2001 a dezembro de 2004, mediante recortes dos dois anos finais de um governo e dois anos iniciais de outro, foram identificadas 69 ações que promoviam a igualdade racial. Dessas, 23 eram do governo federal e 21 , de governos municipais e estaduais, somando, ao todo, 33 ações voltadas para a área da educação. 
Portanto, as políticas afirmativas estão num processo que só conseguiremos avaliar a longo prazo. Tais políticas, no Brasil, podem ser observadas em diversas áreas, tais como, educação, mercado de trabalho e iniciativa privada. Mas é, na educação, que as ações estão mais concentradas, principalmente na questão do acesso e permanência dos estudantes negros nas universidades.

\section{AS AÇÕES AFIRMATIVAS NO CONTEXTO UNIVERSITÁRIO DA FURG: ANÁLISE E DISCUSSÕES}

As Ações Afirmativas na Universidade Federal do Rio Grande - FURG - surgem com uma proposta de política afirmativa, hoje, representada pelo Programa de Ações Afirmativas da Universidade. Essa política, inicialmente, buscou a equidade entre a qualidade acadêmica, a diversidade cultural e as inclusões sociais, para que a universidade refletisse sobre sua autonomia, a fim de atentar para as questões sociais que estivessem de acordo com as leis, promovendo a realização das garantias constitucionais.

Percebe-se que o trabalho realizado está sendo construído de maneira participativa, orgânica e constante, contribuindo na construção de uma universidade pública plural, democrática e representativa das camadas sociais de seu País. Tendo sempre por base o dever constitucional do Estado de reparação de danos históricos, a fim de construir uma nação igualitária, melhorando as condições de acesso e permanência para esses estudantes.

A fim de compreender a trajetória dessa implementação na Universidade, faz-se necessário apresentar o surgimento da mesma. A FURG surge, em 1969, da união da escola de Engenharia Industrial (1955), da Faculdade de Ciências Políticas e Econômicas (1958), da Faculdade de Direito (1960) e da Faculdade Católica de Filosofia de Rio Grande (1961), completando, atualmente, 48 anos de existência. E desde 2009, a Universidade, observando os movimentos nacionais que estavam ocorrendo e com base no projeto de gestão defendido pela administração superior da época, iniciou o processo de implementação do Programa de Ação Inclusiva - PROAI (Resolução No 19/2009), que visava oportunizar novas formas de ingressos nos cursos de graduação.

Essa proposta surge como a primeira alternativa de políticas afirmativas na FURG, com o intuito de promover a equidade entre a qualidade acadêmica, a diversidade cultural e as inclusões sociais, a qual refletisse sobre a autonomia universitária, a fim de atentar para as questões sociais. Além disso, tornou-se primordial buscar a adequação com as políticas públicas, promovendo a realização das garantias constitucionais. 
Na ocasião, definiu-se, como proposta do programa, a adoção de uma bonificação aos estudantes, considerando o critério de natureza social, de natureza étnica e mérito individual no contexto das desigualdades sociais, e a disponibilização de cinco vagas específicas a estudantes indígenas, para ingresso em cinco diferentes cursos de graduação. Esse comprometimento com as questões sociais identifica que a universidade é um espaço de transformação da realidade social e, também, de garantia e fortalecimento das políticas públicas no que concerne, em especial, às Ações Afirmativas.

Em 2013, após a avaliação do programa, visando a sua qualificação e a partir da criação da Lei No 12.711/2012, que trata da Reserva de Vagas a Estudantes Egressos de Escolas da Rede Pública nas Universidades Federais e Institutos Federais, o PROAI necessitou passar por alterações. Assim, o PROAI foi reestruturado como Programa de Ações Afirmativas - PROAAf (Resolução N 20/2013), que apresenta adequações como o aumento para dez vagas para o ingresso de estudantes indígenas; dez vagas para o ingresso de estudantes quilombolas por processo seletivo específico e a reserva de $5 \%$ das vagas às pessoas com deficiência na Universidade.

Cabe destacar que os estudantes ingressantes pelo PROAAf são atendidos pela FURG através da Pró-Reitoria de Assuntos Estudantis - PRAE, a partir de suas demandas, recebendo acompanhamento para permanência por meio do Programa Institucional de Desenvolvimento do Estudante - PDE (Deliberação 157/2010), que tem por finalidade promover o desenvolvimento pleno do estudante universitário regularmente matriculado na FURG, estruturando-se em três subprogramas: assistência básica; apoio pedagógico e formação ampliada. Nesse sentido, os estudantes têm a sua disposição os serviços de acompanhamento pedagógico, social e psicológico, bem como diversos projetos e programas criados para que potencialize seu desempenho, sua formação profissional e a futura atuação na sociedade.

Desde 2013, com a reorganização da estrutura da Pró-Reitoria de Assuntos Estudantis - PRAE, vinculada à Diretoria de Desenvolvimento do Estudante - DIDES, surge a Coordenação de Ações Afirmativas - CAAF/ DIDES/ PRAE. A Coordenação assume a finalidade de garantir os princípios de equidade social entre os estudantes, e como acompanha as ações já implementadas junto às comunidades e grupos tradicionais na Universidade.

Outra política afirmativa que a FURG adota é com relação ao uso do nome social para estudantes travestis e transexuais no âmbito da Universidade, norteada 
pela Deliberação 44/2012 - COEPEA e pela Instrução Normativa $n^{\circ}$ 03/2012 - que tratam da utilização do nome social no âmbito da FURG, cujos procedimentos estarão sob responsabilidade da Pró-Reitoria de Graduação - PROGRAD. Pela Instrução Normativa, fica regulamentado e assegurado este direito ao estudante travesti ou transexual, dos cursos de graduação e de pós-graduação, entendendo-se, por "nome social", aquele pelo qual a pessoa travesti ou transexual se identifique e é identificada pela sociedade.

Por isso, considera-se 2009 um dos marcos na história da nossa Universidade, com relação ao início das Ações Afirmativas. Foi nesse período que criaram vagas para os estudantes cotistas e o processo seletivo específico para indígenas (e logo no ano 2013 para os quilombolas), cuja diversidade reescreveu uma nova "página” em nossa Universidade. Essa política, inicialmente, buscou a equidade entre a qualidade acadêmica, a diversidade cultural e as inclusões sociais, para que a universidade refletisse sobre sua autonomia, a fim de atentar para as questões sociais que estivesse de acordo com as leis, promovendo a realização das garantias constitucionais.

Embora seja pouco tempo do desenvolvimento destas políticas de Ações Afirmativas na FURG, o trabalho realizado está em construção e busca contribuir na formação de uma universidade pública popular e democrática. Nesse viés, buscando sempre por base o dever constitucional do Estado de reparação de danos históricos, a fim de construir uma nação igualitária, melhorando as condições de acesso e permanência para esses estudantes. As Ações Afirmativas transformam espaços em anúncios, mas também em denúncias, uma vez que visam a uma Universidade para todos, mas que nem todos aceitam, tornando-se uma luta diária a maioria das vezes.

$\mathrm{Na}$ verdade, as Ações Afirmativas buscam garantir que haja um desenvolvimento integral do humano, que, consequentemente, desenvolve o crescimento local e global em todos os aspectos que possamos imaginar. E a FURG busca, mediante inúmeras ações, proporcionar condições para a construção de um ambiente de crescimento e desenvolvimento humano para esses estudantes, a fim de consolidar o seu compromisso com as políticas de Ações Afirmativas. Isso vai ao encontro do que defende Fonseca quando afirma que é importante sempre questionar o papel social da universidade. Segundo o referido autor:

As universidades têm um papel e uma função social e política a cumprir no desenvolvimento tecnológico, científico, cultural, econômico, institucional e político do Estado, na medida em que estruturam também as bases de nossa soberania nacional: criação, renovação e difusão de conhecimento. (FONSECA, 2009, p. 99). 
Para consolidar esse papel, a FURG busca realizar um processo participativo de todos os segmentos, respeitando a autonomia dos sujeitos envolvidos. Nestes termos, o referido processo está fundamentado nas contribuições de Paulo Freire sobre diretividade, diálogo e humanização com os sujeitos envolvidos, isto é, em ações fundamentadas nos princípios da educação emancipadora e crítica:

Por isto o diálogo é uma exigência existencial. E, se ele é o encontro em que se solidariza o refletir e o agir de seus sujeitos endereçados ao mundo a ser transformado e humanizado, não pode reduzir-se a um ato de depositar ideias de um sujeito no outro, nem tampouco tornar-se simples troca de ideias a serem consumidas pelos permutantes. (FREIRE, 1987, p. 45).

Tais ações valorizam o saber adquirido na experiência social e cultural que direcionam para novas aprendizagens e, consequentemente, reforçam a necessidade de promoção de políticas institucionais que promovam a permanência, a formação acadêmica dos seus estudantes e a transformação da comunidade em geral. O diálogo, que é base na educação, apresenta-se numa perspectiva transformadora, porque só nos educamos/aprendemos dialogando em um conjunto de relações, pelas quais nos definimos como seres sociais e planetários.

Segundo Paulo Freire, em seu livro Pedagogia do Oprimido, é importante defendermos uma pedagogia que promova a emancipação dos sujeitos, seja por intermédio de lutas, seja pela sua própria libertação. Contudo, isso só terá significado e sentido se os próprios oprimidos se empenharem na reconstrução de sua humanidade, buscando "[...] a grande tarefa humanística e histórica dos oprimidos-libertar-se a si e aos opressores" (FREIRE, 1987, p.30).

Nesta lógica, as Ações Afirmativas surgem para promover a inclusão dos grupos historicamente marginalizados, afirmando suas identidades perante a sociedade em geral e consolidando a diversidade e a pluralidade, principalmente no ensino superior, que até pouco tempo era elitista. Reforça-se, assim, a importância de entender e viver a Universidade como espaço de reivindicações, de luta, compreendendo que a mesma tem um papel social com o potencial de transformar a história da sociedade e a trajetória das Ações Afirmativas.

\section{CONSIDERAÇÕES FINAIS}

As diversas políticas afirmativas que a FURG vem desenvolvendo nos últimos anos reforça o compromisso da Universidade com a permanência efetiva dos estudantes em geral 
e dos estudantes ingressantes pelas Ações Afirmativas em especial. Os espaços que oportunizam os debates sobre as diferentes experiências de diversidade vivenciadas estão sendo promovidos cada vez mais e caminham para o protagonismo e a emancipação dos estudantes, possibilitando, entre outros aspectos, uma reflexão acerca dos diferentes aspectos da diversidade presentes na Universidade.

Dessa forma, as Ações Afirmativas desconstroem discursos, acarretando a reinvenção de novas práticas educativas e relações interpessoais na Universidade. Por vezes, torna-se uma política discriminada por não oportunizarem a reflexão sobre o assunto. Assim, a FURG vem se constituindo como espaço de diálogo, de promoção de políticas, a exemplo dos fóruns institucionais, muitos deles organizados pelos próprios estudantes, reivindicando a garantia de seus direitos dentro e fora da Universidade. Mostras culturais, aulas de dança, sessões de cinema, palestras, oficinas, cursos reforçam culturas, são ações que reafirmam posições e fazem com que a comunidade acadêmica reflita sobre questões como preconceito, diversidade, autonomia e inclusão.

Logo, a política de Ações Afirmativas se constitui numa perspectiva de emancipação do sujeito, em que a busca da superação da relação contraditória opressor-oprimido consiga atingir uma nova ordem social, construída em conformidade com a liberdade e igualdade. Enfim, é preciso compreender que o primeiro movimento no âmbito universitário pelos estudantes é estudar, resignificando e afirmando os espaços de ensino-aprendizagem que, através de tanta luta, foram conquistados.

Portanto, uma das maneiras de combater as desigualdades existentes no nosso País é por meio de políticas públicas direcionadas e específicas, principalmente no ensino superior. Reforçando, assim, a importância de entender e viver a Universidade como espaço de reivindicações, de luta, entendendo que a mesma tem um papel social com o potencial de transformar a história da sociedade. Mudanças tão significativas como esta se processam entre avanços e retrocessos, mas são importantes para manter a discussão e compreender os passos dados nessa trajetória.

\section{REFERÊNCIAS}

BRANDÃO, C. da F. As Cotas na universidade pública brasileira: será esse o caminho? Campinas, SP: Autores Associados, 2005.

BRASIL, Senado Federal. Constituição da República Federativa do Brasil. Brasília, 1988.

BRASIL, Senado Federal. Lei $\mathbf{n}^{\circ} \mathbf{8 . 1 1 2}$, de 11 de dezembro de 1990. Dispõe sobre o regime jurídico dos servidores públicos civis da União, das autarquias e das fundações públicas federais. 
BRASIL, Senado Federal. Lei $\mathbf{n}^{\circ}$ 9.795, de 27 de abril de 1999. Dispõe sobre a Educação Ambiental, Institui a Política Nacional de Educação Ambiental e dá outras providências.

BRASIL, Senado Federal. Decreto $\mathbf{n}^{\mathbf{0}}$ 4.228, de 13 de maio de 2002. Institui, no âmbito da Administração Pública Federal, o Programa Nacional de Ações Afirmativas e dá outras providências.

BRASIL. Ministério da Educação e Cultura. Lei no 12.711, de 29 de agosto de 2012. Dispõe sobre o ingresso nas universidades federais e nas instituições federais de ensino técnico de nível médio e dá outras providências. Disponível em: https://presrepublica.jusbrasil.com.br/legislacao/1032851/lei12711-12. Acesso em 01 de dezembro de 2015.

BRASIL. Ministério da Educação e Cultura. Decreto no 7.824/ 2012. Dispõe sobre o ingresso nas universidades federais e nas instituições federais de ensino técnico de nível médio. Disponível em: https://www2.camara.leg.br/legin/fed/decret/2012/decreto-7824-11-outubro-2012-774384-normape.html. Acesso em 01 de dezembro de 2015.

FERES JUNIOR, J.; ZONINSEIN, J, (orgs). Ação Afirmativa e universidade: experiências nacionais comparadas. Brasília: Editora Universidade de Brasília, 2006.

FONSECA, D. J. Políticas públicas e Ações afirmativas. São Paulo: Selo Negro, 2009.

FREIRE, Paulo. Pedagogia do oprimido. 17. ed. Rio de Janeiro: Paz e Terra, 1987.

Pedagogia da Esperança: Um reencontro com a Pedagogia do Oprimido Rio de Janeiro: Paz e Terra, 1992. Terra, 2006.

Pedagogia da Autonomia: saberes necessários à prática educativa. São Paulo: Paz e

FURG, Universidade Federal do Rio Grande. Programa Institucional de Desenvolvimento do Estudante - PDE. Deliberação 157/2010. Disponível em: http://www.conselho.furg.br/converte. php?arquivo=delibera/coepea/15710.htm. Acesso em 30 de novembro de 2015.

Universidade Federal do Rio Grande. Dispõe sobre a utilização do nome social no âmbito da FURG. Instrução Normativa $\mathrm{N}^{\circ}$ 04/2013. Disponível em: http://www.conselho.furg.br/converte. php?arquivo=instrucoes/prograd/00413.htm. Acesso em 30 de novembro de 2015.

Universidade Federal do Rio Grande. Programa de Ações Afirmativas - PROAAf. Resolução $n^{\circ}$ 020/2013, Conselho Universitário em 22 de novembro de 2013. Disponível em: http://www.conselho.furg.br/converte.php?arquivo=delibera/consun/02013.htm. Acesso em 30 de novembro de 2015.

Universidade Federal do Rio Grande. Programa de Ação Inclusiva PROAI. Resolução $\overline{\mathrm{n}^{\circ}}$ 019/2009, Conselho Universitário em 14 de agosto de 2009. Disponível em: http://www.conselho.furg.br/delibera/consun/01909.htm. Acesso em 30 de novembro de 2015.

LOUREIRO, Carlos F. Trajetórias e Fundamentos da Educação Ambiental. São Paulo: Cortez, 2004.

MINAYO, M.C. de S. O desafio do conhecimento: Pesquisa Qualitativa em Saúde. (12 edição). São Paulo: Hucitec - Abrasco, 2010. 